DOSSIÊ TEMÁTICO: Formação inicial de professores em contextos escolares e binômio teoria/prática nos estágios supervisionados

do1 https://doi.org/10.22481/rpe.v16i43.6777

\title{
PROFESSORES ORIENTADORES DOS ESTÁGIOS SUPERVISIONADOS DAS LICENCIATURAS DO BRASIL: ANÁLISE DE TESES NACIONAIS 2014 - 2018
}

\author{
PRE-SERVICE TEACHING UNDERGRADUTE COURSES PRACTICUM ADVISORS IN \\ BRAZIL: ANALYSIS OF NATIONAL DOCTORAL THESIS 2014 - 2018 \\ PROFESORES TUTORES DE PASANTÍAS SUPERVISADAS DE LICENCIAS \\ BRASILEÑAS: ANÁLISIS DE LA TESIS NACIONAL 2014-2018
}

Emerson Augusto de Medeiros
Universidade Federal Rural do Semi-Árido, campus Mossoró - Brasil

Ivan Fortunato

Instituto Federal de São Paulo, campus Itapetininga - Brasil

Osmar Hélio Alves Araújo

Universidade Federal da Paraíba, campus IV - Brasil

\begin{abstract}
Resumo: Esta pesquisa, a partir de um levantamento documental, analisou teses disponibilizadas no Catálogo de Teses e Dissertações da Coordenação de Aperfeiçoamento de Pessoal de Nível Superior, a CAPES, com foco nos professores orientadores de estágios supervisionados das licenciaturas. A questão norteadora deste estudo é: o que apontam as teses no tocante aos professores orientadores dos estágios supervisionados, seu papel formador no contexto dos estágios nas licenciaturas? Em termos metodológicos, analisamos o conjunto de seis produções doutorais por meio da abordagem qualitativa de pesquisa e da análise documental como técnica de coleta de dados. Como consideração principal, a partir do que apontam as teses, enfatizamos que a orientação nos estágios supervisionados nos cursos de licenciatura do Brasil deve ser concebida como orientação formativa, isto é, como práxis educativa. Compreendemos que esse entendimento ajuda a pensarmos os processos organicamente articulados de formação inicial docente, sem o dualismo que separa a teoria da prática.
\end{abstract}

Palavras-chave: Estágios Supervisionados; Professores Orientadores; Formação Inicial de Professores.

Abstract: This research, based on a documentary inventory, analyzed doctoral thesis available in the Catalog of Thesis and Dissertations of the Coordination for the Improvement of Higher Education Personnel, CAPES, with a focus on pre-service teaching undergradute courses practicum advisors. The guiding question of this study is: what do the thesis point out regarding the pre-service teaching undergradute courses practicum advisors, their training role in the context of internships in pre-service teaching courses? In methodological terms, we analyzed the set of six doctoral thesis using the 
qualitative research approach and documentary analysis as a data collection technique. As a main consideration, based on what the thesis point out, we emphasize that practicum advising in Brazilian pre-service teaching courses should be conceived as formative guidance, that is, as an educational praxis. We understand that this concept helps us to think about the organically articulated processes of initial teacher education, without the dualism that separates theory from practice.

Keywords: Practicum; Advisor Teachers; Initial Teacher Training.

Resumen: Esta investigación, basada en una encuesta documental, analizó las tesis disponibles en el Catálogo de Tesis y Disertaciones de la Coordinación para el Mejoramiento del Personal de Educación Superior, CAPES, enfocándose en supervisores de pasantías supervisadas para cursos de pregrado. La pregunta guía de este estudio es: ¿qué señalan las tesis con respecto a los maestros supervisores de pasantías supervisadas, su papel de capacitación en el contexto de pasantías en cursos de pregrado? En términos metodológicos, analizamos el conjunto de seis producciones doctorales utilizando el enfoque de investigación cualitativa y el análisis documental como técnica de recopilación de datos. Como consideración principal, en base a lo que señalan las tesis, enfatizamos que la orientación en pasantías supervisadas en cursos de pregrado brasileños debe concebirse como orientación formativa, es decir, como praxis educativa. Entendemos que esta comprensión nos ayuda a pensar en los procesos orgánicamente articulados de la formación inicial del profesorado, sin el dualismo que separa la teoría de la práctica.

Palabras clave: Pasantías supervisadas; Profesores rectores; Formación inicial del profesorado.

\section{Introdução}

Este artigo trata do estágio supervisionado nas licenciaturas, cuja definição conceitual pode ser encontrada na literatura especializada, de modo abundante e consubstanciada (LIMA, 2012; PIMENTA; LIMA, 2017). No cenário desse debate, o estágio é entendido sempre como uma experiência coletiva, a qual envolve a tríade licenciandos, professores orientadores e professores supervisores das escolas onde se desenvolvem as atividades de estágio ${ }^{1}$. Entretanto, o estágio nem sempre se traduz, de fato, como uma experiência dialógica, haja vista condições amiúde difíceis das escolas de Educação Básica para a efetivação dos estágios como uma experiência coletiva, assim como pelas dificuldades existentes para o diálogo entre os estudantes, os professores orientadores e os professores supervisores das escolas, espaços de desenvolvimento dos estágios.

\footnotetext{
${ }^{1}$ Usamos a expressão 'professor orientador' para fazermos alusão ao(s) professor(es) dos estágios supervionados das Instituições de Ensino Superior (IES), e professor supervisor para os professores regentes das escolas de Educação Básica. Apesar desta nomenclatura estar expressa no art. $3^{\circ}$, inciso III, $\S^{\circ}{ }^{\circ}$ da Lei Federal 11.788 de 2008, conhecida como "lei do estágio", esses profissionais recebem outras designações conforme às Instituições de Ensino Superior (IES) nas quais se vinculam, no âmbito nacional brasileiro.
} 
Costumeiramente, menciona-se na literatura educacional brasileira a necessidade de uma maior articulação entre as universidades e as escolas; os estudantes, os professores orientadores e os professores supervisores das escolas de Educação Básica. Nesse sentido, a literatura tem apontado os estágios como um dos eixos de aproximação entre as universidades e as escolas (DANIEL, 2009; PIMENTA; LIMA, 2017). Mas, muitas vezes, não fica entendível o papel dos professores orientadores dos estágios, além de não haver condições de trabalho e de formação profissional. Além do mais, não se reconhece devidamente o papel e a função formadora dos professores supervisores das escolas, loci de promoção dos estágios. Assim, apesar de compartilharem a responsabilidade pelo mesmo processo, os estudantes, os professores orientadores e os professores supervisores, muitas vezes, não constroem uma relação visando à efetivação dos estágios como uma experiência coletiva (MEDEIROS, 2014; NÓVOA, 2017).

Já foi identificado que o estágio supervisionado é pauta de interesse de muitos pesquisadores, porém, é um tema ainda pouco explorado nas pesquisas educacionais frente a sua complexidade (MEDEIROS, 2014). Nesse cenário, o trabalho dos professores formadores envolvidos com os estágios, seja do professor orientador da Instituição de Ensino Superior (IES), ou do professor supervisor da Educação Básica, é um campo de investigação pouco explorado e discutido, embora ocupe um lugar primário na consolidação dos estágios. Dessa forma, percebemos que há lacunas expressivas há serem vencidas na aproximação entre os estudantes, os professores orientadores e os professores supervisores. Além do mais, há questões antigas ainda sem respostas e novas questões emergentes acerca do trabalho dos professores orientadores, destacando-se, sobretudo, o seu papel na construção e acompanhamento dos estudantes nos estágios. Tais questões precisam ser debatidas.

Assim, busca-se suprir parte dessas lacunas com esta pesquisa, cujo foco são os professores orientadores de estágios supervisionados das licenciaturas. Desenvolvida a partir de um levantamento documental, o propósito é analisar teses disponibilizadas no Catálogo de Teses e Dissertações da Coordenação de Aperfeiçoamento de Pessoal de Nível Superior (CAPES). A questão norteadora foi: o que apontam as teses mais recentes no tocante aos professores orientadores dos estágios supervisionados, e o que argumentam sobre seu papel formador no contexto dos estágios nas licenciaturas? Dessa forma, o objetivo geral desta investigação consistiu em analisar teses recentes com foco nos professores orientadores dos estágios supervisionados para apontar seu papel formador no contexto das licenciaturas.

Este estudo tem justificativa na necessidade da construção de quadros teóricopráticos acerca do papel dos professores orientadores dos estágios, em todas as etapas desse 
processo como uma experiência coletiva de formação. Como já anunciado, o trabalho desses professores é um elemento fundamental no desenvolvimento dos estágios e não pode ser desconsiderado nos momentos em que se discute, se estrutura e se efetiva a formação inicial docente. Assim, desenvolvemos esta pesquisa apoiados em saberes construídos pelas nossas próprias experiências profissionais como professores formadores em cursos de licenciatura, cotejando o vivido com os resultados apontados nas teses.

Para alcançar o objetivo proposto, o artigo foi organizado em quatro seções. $\mathrm{Na}$ primeira discutimos, brevemente, a respeito da construção do problema investigativo que originou a presente pesquisa. Em seguida, apresentamos o processo metodológico de busca das teses. Na terceira seção, discutimos, com base no que apontam as teses, quem são os professores orientadores dos estágios supervisionados dos cursos de licenciatura do Brasil. Na quarta seção, apresentamos notas, considerando a análise documental desenvolvida, a respeito do papel formador dos professores orientadores dos estágios.

Ao final, dialogamos sobre a orientação nos estágios supervisionados, a partir dos achados na análise, almejando contribuir com os demais artigos que compõem o presente número da Revista Práxis Educacional. De tal forma, esperamos que este trabalho some com as reflexões acerca dos estágios supervisionados e dos professores orientadores dos estágios já desenvolvidas, despertando o desejo de novas investigações ou aprofundando aspectos já abordados na literatura acadêmica nacional e internacional.

\section{Construção do problema investigativo - adendo necessário}

Esta pesquisa se situa no campo da formação inicial de professores no Brasil, mais especificamente no âmbito dos estágios supervisionados dos cursos de licenciatura. Como já delineado, dentre os problemas persistentes nos estágios supervisionados na formação inicial dos professores, destacam-se: desarticulação entre a universidade e a escola no desenvolvimento dos estágios; ausência de interação entre os sujeitos envolvidos no processo, estudantes, professores orientadores e professores supervisores das escolas; indefinições em torno do papel formativo dos professores orientadores dos estágios (SARTI, 2012; MEDEIROS, 2014; MARAFELLI; RODRIGUES; BRANDÃO, 2017).

Neste âmbito, um aspecto que nos chama a atenção é o papel dos professores orientadores dos estágios supervisionados. Essa questão problematizadora, como componente essencial desta pesquisa, de certa forma atualiza o trabalho realizado por Medeiros (2014). Segundo a autora, há pouca produção em relação ao papel dos professores orientadores dos 
estágios. Por outro lado, Zeichner (2010) considera que é comum, muitas vezes, os professores orientadores dos estágios conhecerem pouco sobre as práticas educacionais construídas no contexto da Educação Básica. Isso é algo bastante complicado, pois tratam de um ensino divorciado da realidade em que as escolas se veem inseridas, seus problemas reais e suas experiências concretas de ensino. É comum também, por exemplo, que os professores orientadores dos estágios conheçam pouco sobre as especificidades da Pedagogia e da Didática, embora sejam áreas que dialogam diretamente com os estágios.

Isso é sintomático nos casos em que ainda impera a notória segregação conhecida como esquema 3+1 nas licenciaturas (SCHEIBE, 1983), ou seja, o curso é organizado de forma que a maior parte das disciplinas (e respectivos conteúdos) tenha foco exclusivo na ciência para a qual se forma o futuro professor (p. ex. Física, Química, História, Geografia etc.). Nesse esquema, relega-se apenas um quarto do curso à formação pedagógica, sendo essa genérica (as disciplinas seriam comuns a todas as licenciaturas) e superficial (as mais fáceis, consideradas "perfumaria"). Ora, não podemos esquecer que, nos estágios, a formação pedagógica e a formação específica deveriam se fundir numa mesma intencionalidade: fomentar experiências de pesquisa e a construção do conhecimento para a docência.

Mas, há quase duas décadas, Monteiro (2002) afirmava que os professores orientadores dos estágios, muitas vezes, ficavam relegados a meros avaliadores da competência dos futuros profissionais em utilizar técnicas de ensino e recursos pedagógicos, e/ou como meros observadores do cumprimento de regras e normas previamente estabelecidas pela própria instituição formadora. Por outro lado, os estudos de Marafelli, Rodrigues e Brandão (2017) expressam que os professores supervisores das escolas de Educação Básica, muitas vezes, apenas atestam a carga horária de estagio, centrados normalmente na simples observação da sala de aula, sem previsão do debate necessário com os estudantes sobre as práticas observadas.

Não há, portanto, possibilidades de se pensar possíveis transformações nos estágios supervisionados sem envolver estudos sistemáticos acerca dos problemas e desafios que perpassam o trabalho dos professores orientadores dos estágios supervisionados nas licenciaturas. Dentre eles, como constatou Medeiros (2014), o elevado número de estudantes atendidos por cada professor orientador; o acúmulo de trabalho (correção de diários, de planos de atividades, acompanhamento in loco); e a ausência de momentos para reflexão.

Partindo dessas considerações, a seguinte questão aparece como central, para nortear a produção deste texto: quem são os professores orientadores dos estágios supervisionados e qual seu papel formador nas licenciaturas do Brasil? 
Ao buscar respostas, esperamos contribuir para a reflexão e a defesa de teorias, práticas, reflexões epistemológicas e sociais que apontem para a (re) configuração da identidade profissional dos professores orientadores dos estágios, destacando sua participação ativa na formação do licenciando pelos caminhos da produção do conhecimento docente, a partir das experiências concretas no chão da escola, vividas no contexto do estágio supervisionado.

\section{Percurso metodológico}

Para tentar responder às inquietações emergentes a respeito de quem é e o que deve fazer um professor orientador de estágio supervisionado nas licenciaturas, buscamos respostas na produção mais recente da pós-graduação nacional. Assim, tal qual pesquisa anterior (MONTEIRO; FORTUNATO, 2019), realizamos um inventário a partir do Catálogo de Teses e Dissertações da Coordenação de Aperfeiçoamento de Pessoal de Nível Superior, a CAPES, com foco nos estágios supervisionados das licenciaturas, sobretudo, buscando as pesquisas que versam sobre os professores orientadores dos estágios. A realização deste inventário se deu a partir das seguintes etapas:

I. Delimitação dos descritores de busca. Inicialmente, foi pensando em se utilizar "professor orientador" ou somente "orientador", combinado(s) por meio do operador booleano AND com um ou mais dos seguintes termos: "estágio", "estágio curricular", “estágio supervisionado" e/ou "licenciatura". Percebemos que tais descritores deixavam de fora teses desenvolvidas com mais de um professor, portanto, fizemos combinações também no plural, ou seja, "professores orientadores" e "orientadores". Além disso, tais descritores não contemplavam as "professoras orientadoras" ou “orientadoras", sendo tais descritores incluídos na busca. Assim, foram realizadas quatorze combinações ${ }^{2}$ com esses descritores, levando a um total de 720 produções;

II. Em seguida, realizamos dupla filtragem: (a.) por data, concentrando os achados entre os anos de 2014 e 2018, com o objetivo de encontrar a produção mais recente; e (b.) por tipo, selecionando apenas teses, porque são pesquisas de maior fôlego, sendo realizadas ao longo de quatro anos, em média. O número reduziu, então, para 76;

${ }^{2}$ A busca foi realizada no site: https://catalogodeteses.capes.gov.br/, com acesso em março de 2020. 
III. Na terceira etapa, eliminamos as teses duplicadas e realizamos mais quatro filtragens: (a.) acesso digital, excluindo as teses que não estavam disponíveis online nas bibliotecas depositárias; (b.) análise de título, excluindo as teses que não tinham o estágio como objeto central e/ou já denunciavam ter foco exclusivo no licenciando em fase de realização do estágio; (c.) análise do resumo, excluindo as teses que apenas mencionavam a existência de um/a professor/a orientador/a; (d.) análise transversal da tese completa, excluindo as teses que inferiam a respeito do trabalho realizado pelos/as orientadores/as, mas não dedicavam espaço, no texto, para discutir as responsabilidades, os saberes, as preocupações etc. Assim, ao final desse processo de filtragem, restaram seis teses inventariadas.

Dessa forma, de posse dessas seis teses, prosseguimos com a leitura de capítulos dos textos (ou das teses na totalidade), objetivando responder ao problema investigativo apresentado em outra seção, a respeito dos apontamentos mais recentes sobre os professores orientadores e seu papel como formador nas licenciaturas.

Assim, a partir do problema investigativo, demarcamos dois eixos centrais para a análise. O primeiro confere a "quem são os professores orientadores dos estágios supervisionados dos Cursos de licenciaturas do Brasil" e o segundo condiz ao seu "papel formador no contexto dos estágios”. Registramos também que a leitura dos documentos selecionados permitiu-nos aprofundar, para além da questão central deste estudo, outras questões sobre os estágios supervisionados nas Licenciaturas no País, bem como sobre a docência universitária, a formação inicial de professores da Educação Básica e a Educação Superior. Tal como Gatti (2014 apud ANDRÉ, 2017), compreendemos que o propósito da pesquisa em Educação é, entre outros, “evidenciar realidades a partir de uma perspectiva teórica dada, validar teorias, criar novo ramo explicativo, levantar lacunas na teoria, propor outra ótica explicativa" (p. 832) e/ou aprofundar questões educacionais, culturais, sociais e políticas existentes num dado contexto histórico.

\section{Professores orientadores dos estágios supervisionados de licenciaturas do Brasil - o que apontam as teses nacionais (2014 - 2018)?}

Para adentrarmos na análise das produções, organizamos o Quadro 1 a seguir, com informações importantes das pesquisas inventariadas, as quais nos permitem entender em que contextos foram materializadas, os objetivos das investigações, entre outras informações. 
Quadro 1 - Teses sobre professores orientadores de estágios de licenciatura do Brasil (2014-2018)

\begin{tabular}{|c|c|c|c|}
\hline Título & Autoria e orientação & Universidade & Objetivos do Estudo \\
\hline $\begin{array}{l}\text { Estágio Curricular } \\
\text { Supervisionado no } \\
\text { Curso de Pedagogia da } \\
\text { UFPI: tessituras da } \\
\text { relação teoria e prática } \\
\text { na formação de } \\
\text { professores }\end{array}$ & $\begin{array}{l}\text { Maria do Socorro } \\
\text { Soares (2016) } \\
\\
\text { Orientação: Monique } \\
\text { Adries Nogueira }\end{array}$ & $\begin{array}{c}\text { Universidade Federal } \\
\text { do Rio de Janeiro - } \\
\text { UFRJ } \\
\text { Educação }\end{array}$ & $\begin{array}{c}\text { Investigar a estruturação e } \\
\text { desenvolvimento do estágio } \\
\text { curricular do curso de Pedagogia, } \\
\text { na Universidade Federal do Piauí, } \\
\text { campus Ministro Petrônio Portela, } \\
\text { em Teresina, a partir da } \\
\text { concepção de estágio de } \\
\text { professores orientadores e } \\
\text { supervisores. }\end{array}$ \\
\hline $\begin{array}{c}\text { Professoras } \\
\text { Orientadoras de } \\
\text { Estágio Supervisionado } \\
\text { em Curso de } \\
\text { Pedagogia: } \\
\text { desenvolvimento } \\
\text { profissional docente e } \\
\text { sentidos atribuídos à } \\
\text { função de orientação }\end{array}$ & $\begin{array}{l}\text { Kátia Silene da Silva } \\
\qquad \text { (2017) } \\
\text { Orientação: Renata } \\
\text { Cristina Oliveira } \\
\text { Barrichelo Cunha }\end{array}$ & $\begin{array}{c}\text { Universidade } \\
\text { Metodista de } \\
\text { Piracicaba - UNIMEP } \\
\text { Educação }\end{array}$ & $\begin{array}{l}\text { Compreender o processo de } \\
\text { desenvolvimento profissional de } \\
\text { professoras orientadoras de } \\
\text { Estágio Supervisionado do Curso } \\
\text { de Pedagogia e analisar os } \\
\text { sentidos que elas atribuem à sua } \\
\text { função como orientadoras. }\end{array}$ \\
\hline $\begin{array}{l}\text { Pedagogia Específica } \\
\text { de Orientação de } \\
\text { Estágio: uma } \\
\text { investigação narrativa }\end{array}$ & $\begin{array}{l}\text { Luana Rosalie Stahl } \\
\qquad(2017) \\
\text { Orientação: Silvia } \\
\text { Maria de Aguiar Isaia }\end{array}$ & $\begin{array}{c}\text { Universidade Federal } \\
\text { de Santa Maria - } \\
\text { UFSM } \\
\text { Educação }\end{array}$ & $\begin{array}{l}\text { Compreender de que modo a } \\
\text { pedagogia específica de estágio } \\
\text { curricular supervisionado se } \\
\text { constitui a partir de documentos } \\
\text { oficiais e, principalmente, dos } \\
\text { professores orientadores. }\end{array}$ \\
\hline $\begin{array}{c}\text { Aprendizagem Docente } \\
\text { do Professor } \\
\text { Orientador no Estágio } \\
\text { Curricular } \\
\text { Supervisionado em } \\
\text { Cursos de Licenciatura } \\
\end{array}$ & $\begin{array}{c}\text { Sybelle Regina } \\
\text { Carvalho Pereira } \\
\text { (2017) } \\
\text { Orientação: Doris Pires } \\
\text { Vargas Bolzan } \\
\end{array}$ & $\begin{array}{c}\text { Universidade Federal } \\
\text { de Santa Maria - } \\
\text { UFSM }\end{array}$ & $\begin{array}{l}\text { Compreender como ocorre a } \\
\text { aprendizagem docente do } \\
\text { professor orientador no contexto } \\
\text { do estágio curricular } \\
\text { supervisionado nas licenciaturas. }\end{array}$ \\
\hline $\begin{array}{l}\text { Estágio curricular } \\
\text { supervisionado na } \\
\text { licenciatura em } \\
\text { Matemática: um } \\
\text { componente curricular } \\
\text { em discussão }\end{array}$ & $\begin{array}{l}\text { Iara Zimmer (2018) } \\
\text { Orientação: Bárbara } \\
\text { Lutaif Bianchini }\end{array}$ & $\begin{array}{c}\text { Pontifícia Universidade } \\
\text { Católica de São Paulo } \\
\text { - PUC/SP } \\
\text { Educação Matemática }\end{array}$ & $\begin{array}{l}\text { Investigar o estágio curricular em } \\
\text { licenciaturas em matemática por } \\
\text { meio de entrevistas com sete } \\
\text { professores orientadores e } 20 \\
\text { estagiários, buscando identificar o } \\
\text { estágio como espaço fundamental } \\
\text { na formação docente. }\end{array}$ \\
\hline $\begin{array}{l}\text { Os Saberes Docentes } \\
\text { do Orientador de } \\
\text { Estágio Curricular do } \\
\text { Curso de Licenciatura } \\
\text { em Geografia }\end{array}$ & $\begin{array}{l}\text { Luzianny Borges } \\
\text { Rocha (2018) } \\
\text { Orientação: Luis } \\
\text { Távora Furtado Ribeiro }\end{array}$ & $\begin{array}{l}\text { Universidade Federal } \\
\text { do Ceará - UFC }\end{array}$ & $\begin{array}{l}\text { Compreender os saberes do } \\
\text { orientador de estágio curricular do } \\
\text { Curso de Licenciatura em } \\
\text { Geografia da UFC, } \\
\text { correlacionando com a sua } \\
\text { formação e prática docente no } \\
\text { contexto de práxis. }\end{array}$ \\
\hline
\end{tabular}

Fonte: Dados da pesquisa, 2020.

Em primeira referência, destacamos que o conjunto de produções se detém aos professores orientadores dos estágios supervisionados de cursos de licenciatura diferentes. Nesse rol, abordam a atuação docente nos Cursos de Licenciatura em Pedagogia, Matemática, Letras, Geografia, Física, entre outros. Esse aspecto inicial aponta que o interesse pelo tema, por parte dos investigadores educacionais, se situa não unicamente em uma área/disciplina específica do conhecimento. Outra característica condiz ao fato de as produções terem sido 
desenvolvidas em programas de pós-graduação em Educação e instituições diversas, as quais envolvem as esferas pública e privada, bem como instituições de educação superior localizadas em três regiões brasileiras: sudeste, sul e nordeste.

Aproximando-nos do primeiro eixo central da questão norteadora da pesquisa, o qual condiz a "quem são os professores orientadores dos estágios supervisionados dos cursos de licenciatura do Brasil", inferimos que uma característica acentuada nas teses se refere à presença feminina na condição de "professor orientador". Das seis teses analisadas, em quatro delas os participantes/sujeitos das investigações conferem, em maioria, a serem mulheres. Alertamos que o estudo de Rocha (2018), ao investigar os saberes docentes de três professores orientadores dos estágios supervisionados da Licenciatura em Geografia da Universidade Federal do Ceará - UFC, e a pesquisa doutoral de Stahl (2017), ao se concentrar em quatorze professores dos estágios supervisionados de quatorze cursos de licenciatura da Universidade Federal de Santa Maria - UFSM, não evidenciaram, textualmente, o gênero dos participantes das pesquisas. Eles são abordados de modo genérico, sem evidências que nos situem acerca do aspecto.

De forma geral, pela leitura das teses, o indicativo de que os professores orientadores dos estágios supervisionados abordados nas investigações são, em maioria, do sexo feminino se fez presente. Essa consideração pesa para a compreensão de que nos contextos dos estágios supervisionados das licenciaturas do Brasil tal característica pode ser validada. Reforçamos que a feminização do magistério, em especial, na Educação Básica é referência apontada em várias investigações publicadas tanto nas pesquisas na área de Educação, como em estudos no campo da Sociologia (CUNHA, 2012).

A despeito desse aspecto, Carvalho (1996), Louro (1997) e Cunha (2012), se baseando em investigações realizadas sobre o processo histórico de feminização do magistério no Brasil, adicionam que a partir do século XIX a profissão professor tornou-se um elemento representativo do trabalho desenvolvido por mulheres. Por questões também de poder, de dominação e de hierarquização ao largo da história entre grupos sociais, culturais e, sobretudo, acerca da divisão do trabalho entre homens e mulheres no País, algumas profissões que no início da construção da sociedade brasileira eram caracterizadas como representadas pelos homens - a exemplo da profissão professor, que no período de colonização do Brasil com os jesuítas tinha os docentes caracterizados no sexo masculino -, se tornaram referência ao trabalho da mulher.

Quando associamos essa conjuntura à realidade dos professores orientadores dos estágios supervisionados, com base no que indicam as teses, supomos que a feminização do 
magistério, aspecto evidente no contexto histórico da Educação Básica (GATTI; BARRETTO, 2009; GATTI et al., 2019), se apresenta no âmbito da Educação Superior, nos cursos de licenciatura.

$\mathrm{Na}$ continuidade da análise, constatamos que, além dos professores orientadores dos estágios supervisionados, participantes das pesquisas, serem, na maior parte, do sexo feminino, eles assumiram a área de estágio nos cursos de licenciatura tendo como justificativa maior já terem experiências profissionais na Educação Básica, em diferentes modalidades (Educação de Jovens e Adultos, Educação Rural, Educação Especial) e etapas (Educação Infantil, Ensino Fundamental e Ensino Médio). O que inferimos é que na maioria das pesquisas (quatro teses), destaca-se que os professores orientadores se inseriram no âmbito do estágio supervisionado porque já possuíam experiências com a Educação Básica e tinham a intenção de continuarem estabelecendo diálogos com a referida etapa de ensino, o que somaria para a construção de pesquisas no Ensino Básico e para o seu crescimento profissional.

No entanto, há teses, conforme consta em Silva (2017), que notificam que o vínculo dos professores orientadores com a área de estágio supervisionado se deu a partir da aprovação em concurso público, não havendo possibilidades de assumirem outras disciplinas nas licenciaturas após a inserção no cargo profissional. Também é relatado no estudo da autora que os professores orientadores dos estágios se associaram a essa área de formação nas licenciaturas por já terem ministrado, anteriormente à atuação nos estágios, disciplinas de Práticas de Ensino e Didática nas graduações. Ainda, é afirmado em Silva (2017) que o vínculo dos professores orientadores com os estágios supervisionados se fez por escolha da própria unidade acadêmica em que os docentes estão alocados, restando a eles contribuírem com o seu desenvolvimento nos cursos.

Sobre os aspectos registrados nos parágrafos antecedentes, vimos, com respaldo no que registram as pesquisas doutorais analisadas, que a atuação docente na Educação Básica, anterior à atuação na Educação Superior, é determinante, por parte dos docentes, para o interesse em se vincular à orientação de estágio nos cursos de licenciatura, o que contraria, em parte, o estudo de Zeichner (2010) quanto a essa questão.

De nossa parte, na condição de docentes de cursos de licenciatura, o desejo de atuar no âmbito dos estágios supervisionados, no decurso de nossa experiência profissional no Ensino Superior, se justifica tanto pela aproximação que nos é proporcionada com a Educação Básica - o que contribui para a produção de diferentes saberes e conhecimentos de cunho educacional e pedagógico acerca da área (Educação Básica) para a qual vislumbramos formar 
professores -, quanto pelas experiências construídas no Ensino Básico em momentos anteriores de nossas trajetórias profissionais. Sabemos da relevância que os estágios ocupam nos cursos de formação docente, principalmente pela oportunidade de vivências dos estagiários com as diferentes realidades educacionais, quer no cotidiano das escolas, quer na sala de aula (SOARES, 2016). A orientação nos estágios supervisionados é um dispositivo que nos qualifica acerca da prática educacional exercida no Brasil.

Vimos, nas teses, inferências salientadas quanto à predominância da associação do vínculo de atuação na orientação dos estágios se concretizar sob a influência das experiências profissionais anteriores na Educação Básica, por parte dos professores orientadores. Mesmo assim, não descartamos, pelos diálogos construídos com diferentes alunos de cursos de licenciatura e colegas de nossos entornos laborais, que nem sempre os docentes orientadores possuem a vivência e, principalmente, uma leitura sensível sobre/com a Educação Básica. Compreendemos que o distanciamento entre universidade e escola nos processos de formação inicial docente se faz não somente pela ausência de ações institucionais que demarquem esse objetivo. No nosso entendimento, há uma grande parcela de professores formadores, no caso os professores orientadores dos estágios, que desconhece o chão das instituições de Educação Básica, lócus primordial da formação inicial dos professores.

Dando prosseguimento à análise, importa-nos situar que outra característica emergente dos trabalhos doutorais, referente a "quem são os professores orientadores dos estágios supervisionados dos cursos de licenciatura do Brasil", concerne à sua formação docente. Nesse aspecto, identificamos que, nas seis teses analisadas, os professores orientadores possuem, na maior parte, formação inicial nas áreas dos cursos de licenciatura em que atuam. Já em relação à formação continuada, a nível stricto sensu, principalmente os professores que lecionam em cursos de licenciatura específicos ${ }^{3}$ (Geografia, Física, Letras, entre outros), se desenvolveu em outros domínios para além da área de Educação.

Neste quesito, o que avaliamos, de modo geral, é que os professores orientadores dos estágios supervisionados dos Cursos de Pedagogia, optaram, em grande parte, pela formação stricto sensu na área de Educação. Quando comparamos essa realidade aos professores orientadores dos estágios das licenciaturas específicas, tal constatação não se evidencia. Em maioria, possuem formação continuada nas áreas (subáreas) específicas dos cursos em que lecionam. Vimos que esses docentes constroem e produzem conhecimentos sobre a área de

\footnotetext{
${ }^{3}$ A exceção neste aspecto se deu no estudo de Zimmer (2018). Dos sete professores orientadores, participantes da pesquisa, cinco docentes possuem licenciatura em Matemática e pós-graduação stricto sensu na área de Educação.
} 
Educação no contexto de sua prática profissional (STAHL, 2017; PEREIRA, 2017; ROCHA, 2018), o que inclui a participação em fóruns e/ou núcleos docentes estruturantes das licenciaturas, as atividades de extensão e as orientações em programas/projetos de formação docente destinados à formação inicial de professores da Educação Básica (ZIMMER, 2018), entre outras.

Frente ao cenário descrito, nos preocupamos com a formação pedagógica para atuação nos próprios estágios supervisionados. Mesmo os professores orientadores que exercem a docência nos cursos de Pedagogia e possuem pós-graduação na área de Educação, entendemos que não focam, na maior parte, nos processos da formação stricto sensu, suas ações formativas para atuação nos estágios. Dito isto, interrogamos: quais concepções pedagógicas e teórico-práticas fundamentam as ações dos professores orientadores? Será que as experiências na Educação Básica (característica atestada nas produções doutorais como um dos mecanismos que conduziu os docentes para atuação na orientação dos estágios supervisionados) são suficientes para a produção de conhecimentos pedagógicos e educacionais para atuação nesse âmbito da formação inicial docente?

O último aspecto apresentado nas teses, referente ao eixo em análise, circunscreve para o tempo de atuação dos docentes frente à orientação nos estágios. Como as produções científicas tiveram objetivos investigativos diferentes, verificamos que não há um consenso ou aspectos que apontem proximidades na realidade analisada. De toda forma, apreendemos que na maioria dos trabalhos doutorais (quatro teses), os professores orientadores exercem essa função a muito tempo, entre nove e 24 anos. Esse apontamento analítico nos permite inferir que há uma permanência dos docentes na função de orientação dos estágios supervisionados. Ou seja, após iniciarem na função de orientadores dos estágios permanecem exercendo essa atividade no decurso da trajetória profissional no Ensino Superior.

Tal como exercitamos em outro momento do texto, ilustramos os apontamentos apreendidos na análise das produções doutorais. Destacamos que a Figura 1 apresenta uma leitura representativa acerca de nossa compreensão quanto ao eixo em discussão. Todavia, não devemos generalizar os apontamentos demarcados na sequência. Eles condizem a uma interpretação que produzimos sobre uma realidade atestadas nas seis teses analisadas. 
Figura 1 - Características de professores orientadores de estágios de licenciatura (2014-2018)

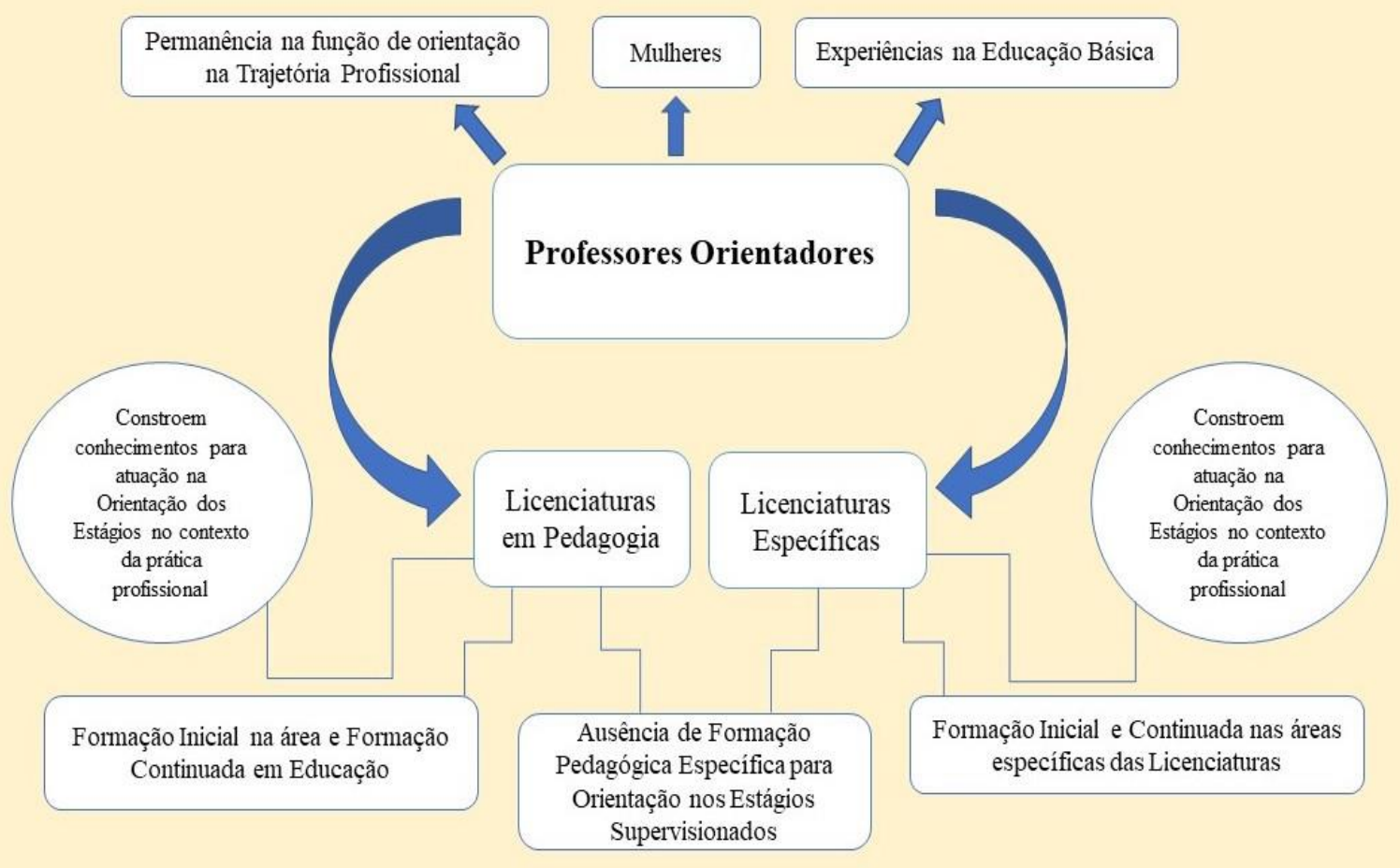

Fonte: Elaborada pelos autores, 2020.

Independentemente das considerações finais acerca do eixo em análise, ponderamos que não há características gerais as quais salientem entendimentos consensuais sobre a identidade profissional dos docentes orientadores dos estágios supervisionados. Na nossa compreensão, há aspectos de natureza profissional que se apresentaram nas teses analisadas como características identitárias dos professores orientadores dos estágios, as quais devem ser pensadas e validadas a partir da análise de questões históricas, sociais, culturais e políticas referentes aos espaços profissionais dos docentes e à profissão professor no Brasil.

\section{O papel formador dos professores orientadores nos estágios supervisionados dos cursos de licenciatura do Brasil}

Em texto publicado na área de Educação, que discute o papel da orientação em pesquisas de pós-graduação, Machado (2012) infere um importante indicativo acerca do trabalho de orientação na Educação Superior: segundo a autora, mesmo com a formação vivenciada, muitas vezes por longos períodos (da graduação à pós-graduação) para atuação no Ensino Superior, os professores orientadores não se tornam suficientemente conhecedores acerca do papel da orientação. Quando nos conduzimos à realidade da orientação nos estágios 
supervisionados nos cursos de licenciatura, nos parece nebuloso o cenário acerca do trabalho de orientação.

Essa afirmativa se sustenta por duas questões: em primeiro lugar, o papel da orientação nos estágios supervisionados é determinado, em grande parte, pela cultura institucional local em que se situa a licenciatura (PIMENTA; LIMA, 2017; LÜDKE; SCOTT, 2018). Em algumas realidades, a ausência de documentos que institucionalize as ações dos estágios limita a atuação dos professores orientadores junto aos estagiários, o que acarreta no desvio das funções da orientação, conduzindo os docentes a sobrelevarem suas energias aos aspectos burocráticos e institucionais, minimizando o trabalho formativo da orientação.

Em segundo lugar, por não existir no interior dos cursos de licenciatura, em especial, nas licenciaturas específicas, uma perspectiva de formação docente que, desde o início das ações formativas nos cursos, conduza os discentes a refletirem sobre a realidade escolar e educacional, atribuem ao estágio o papel de "salvador" da formação inicial docente, o qual oportunizará todas as vivências necessárias ao entendimento da prática profissional que os discentes exercerão quando licenciados (LÜDKE; SCOTT, 2018). Aos docentes orientadores cabe, nesse sentido, cumprirem o papel formativo de desenvolver, de toda forma, atividades e ações que qualifiquem os discentes à realidade escolar que, por sua vez, se mostra sempre complexa e em constante mutação.

$\mathrm{Na}$ leitura e análise dos seis trabalhos doutorais, essas questões se evidenciaram. No entanto, mesmo com o cenário nebuloso acerca do papel formador dos professores orientadores dos estágios supervisionados dos cursos de licenciatura do Brasil, encontramos pontos que convergem para reflexões. A princípio, reforçamos o papel de refletirem com os discentes sobre as vivências que já possuem tanto a nível acadêmico, quanto em nível de experiências na Educação Básica no fito de projetarem novos conhecimentos e (res)significarem as práticas escolares nas/sobre as instituições educacionais. Para esse aspecto, é fundamental que os docentes orientadores possuam sensibilidade e conhecimentos acerca do contextual atual e histórico da sociedade e da escola; da Educação Superior, da universidade, sua cultura organizacional, sua base normativa; conhecimentos sobre as etapas, níveis e modalidades da Educação Básica, do currículo escolar (oficial e praticado); conhecimentos de natureza psicopedagógica, entre outros. Esse entendimento se consolida, com respaldo no que apontam as teses, acerca do papel formador dos professores orientadores. Registramos, na sequência, alguns fragmentos textuais advindos das teses: 
Enquanto professoras da universidade que formam futuros professores, as entrevistadas reconhecem que seu papel na orientação do Estágio Supervisionado é também promover a relação entre a universidade e as escolas de educação básica. Essa aproximação é complexa porque, historicamente, a educação superior é mais valorizada, sendo considerada a instância de produção do conhecimento a ser aplicado na educação básica [...] acreditamos que elas são responsáveis pela valorização da docência na educação básica, como também pela promoção da reflexão crítica e teorização na/da prática. Dessa forma, podem favorecer a elaboração de conhecimentos sobre a docência e a realidade da escola, promovendo a aproximação por meio de um trabalho de colaboração entre a universidade e educação básica. (SILVA, 2017, p. 146-147)

Os docentes reconhecem-se, no contexto da atividade da orientação, como mediadores na apropriação de conhecimentos, atitudes e valores, assumindo a responsabilidade de problematizarem, provocarem e discutirem a área de estudo e os aspectos pedagógicos da formação [...] Acompanhar o processo de planejamento e transposição didática do conteúdo nos processos de ensino e de aprendizagem refere-se à função da orientação, a fim de que o estagiário desenvolva o controle racional das ações didáticas e, consequentemente, consiga atuar de forma consciente nos processos de ensino e aprendizagem de seus alunos [...] Os professores orientadores consideram fundamental interagirem com seus estagiários, a fim de conhecerem sua história de vida; logo, utilizam-se das produções escritas tanto para aprofundar a aprendizagem dos conceitos centrais que envolvem o aprender a ensinar quanto para fortalecerem os vínculos interpessoais no cenário da aula-orientação. (PEREIRA, 2017, p. 235)

São os professores orientadores que assumem a docência, na perspectiva de um curso de licenciatura, sensíveis às questões pertinentes à educação. Articulam a teoria com a prática e assim formam professores com uma compreensão mais ampla do que é a docência. Outrossim, apresentam aos alunos estagiários os desafios da prática docente, com as nuances positivas e negativas, que qualquer profissional, no exercício de uma outra profissão, pode enfrentar. Buscam uma aproximação com o espaço escolar e conhecem de perto não só os sujeitos que fazem a escola, como também os projetos, as políticas e as problemáticas educacionais. Valorizam as experiências dos discentes em formação e as contextualizam com os discursos dos teóricos, com os documentos oficiais, além de os relacionarem com os seus saberes docentes, todos eles. (ROCHA, 2018, p. 120)

O papel formador dos professores orientadores não se resume, pelo que registram as teses, à ação de orientar as atividades a serem desenvolvidas nas instituições escolares, onde se realizam os estágios. Isso porque, tal como a docência na Educação Superior, esse papel é multifacetado, englobando a mediação nas ações e atividades que se desenvolvem entre os diferentes atores/sujeitos que vivenciam os estágios. De modo singular, os professores orientadores exercem com os alunos o papel formativo de conhecer, problematizar, analisar, refletir e buscar mecanismos/ações para a articulação entre a teoria e a prática no cotidiano das escolas e, principalmente, da sala de aula. Esse papel, portanto, não pode ser simplificado, 
haja vista os inúmeros fatores externos e internos à universidade e às escolas que limitam a sua efetivação.

Como apontamento advindo de nossas experiências profissionais, elencamos a tensa e difícil relação, em contextos, construída entre setores acadêmicos, instâncias responsáveis pela institucionalização dos estágios nas licenciaturas, com os alunos e os professores orientadores. Não é incomum a prevalência de normas e manuais de estágios sem diferenciação para cursos de licenciatura e bacharelado. Tal como aponta Rocha (2018), alguns documentos produzidos em universidades no Brasil não consideram a especificidade dos estágios nos cursos de licenciatura e validam prescrições genéricas para todas as graduações.

Ainda sobre o papel formador dos professores orientadores, sublinhamos um conjunto de aspectos abstraídos com a análise documental das produções doutorais. Esses aspectos são um esforço de síntese que realizamos, o qual alerta para o papel formador dos professores orientadores nos estágios, a partir de três dimensões principais, a saber: (a.) pedagógica, (b.) curricular, e (c.) institucional. Vejamos.

a) Dimensão pedagógica:

- Estimular a criticidade e a reflexividade sobre a relação de interdependência do trabalho docente em sala de aula, com a escola, o sistema educacional (local, regional e nacional) e a sociedade. Ou seja, impulsionar a teorização e a reflexão da/na prática escolar (SILVA, 2017; ZIMMER, 2018);

- Proporcionar, por meio da orientação, a análise do cotidiano da sala de aula, bem como da escola, de sua função social e dos desafios contínuos vivenciados por ela (PEREIRA, 2017);

- Orientar e acompanhar situações de insegurança e de conflito sobre a prática docente, especialmente com os discentes que não possuem experiências profissionais na Educação Básica (SOARES, 2016; STAHL, 2017);

- Orientar os discentes na elaboração de planos de aula ou projetos educativos e de ensino, bem como para o uso de ferramentas tecnológicas e de diferentes recursos pedagógicos em sala de aula, no objetivo de suscitar o exercício da reflexão sobre as metodologias e as técnicas de ensino a serem utilizadas com os conteúdos e os conhecimentos curriculares (STAHL, 2017; ZIMMER, 2018); 
- Atuar de forma madura, sensível e equilibrada no processo de orientação do estágio, haja vista que suas práticas (em termos de planejamento, intervenção e avaliação) influenciarão emocionalmente o estagiário (STAHL, 2017);

- Discutir e elaborar com os estagiários propostas de ensino e de aprendizagem com os conceitos das disciplinas específicas do conhecimento (Matemática, História, Geografia, entre outros) trabalhados na Educação Básica, por meio de ações gradativas com os conteúdos curriculares vivenciados na universidade. Tais propostas têm como objetivo ajudar o licenciando a relacionar os conteúdos acadêmicos com os conteúdos escolares, o que lhe permitirá dar sentido a sua formação como um todo (ZIMMER, 2018).

b) Dimensão curricular:

- Promover o trabalho coletivo com os sujeitos de diferentes contextos institucionais na intenção de materializarem ações curriculares interativas no estágio que favoreçam a apreensão da realidade social e educacional (SOARES, 2016; PEREIRA, 2017);

- Contribuir para que haja a interação/integração dos conhecimentos curriculares específicos das áreas de formação com os conhecimentos curriculares pedagógicos e educacionais (ZIMMER, 2018);

- Gerar ações curriculares que centralizem a pesquisa como eixo central dos estágios, uma vez que as experiências de estágios com/como pesquisa apontam ricas aprendizagens à formação inicial docente (SILVA, 2017; PEREIRA, 2017; ROCHA, 2018);

- Configurar ações e atividades curriculares que salientem a valorização do trabalho docente na Educação Básica, angariando romper com a perspectiva dos cursos de licenciatura (especialmente as licenciaturas específicas) que ensinam os conteúdos específicos, mas não qualificam (como deveriam) pedagogicamente os licenciandos (STAHL, 2017).

c) Dimensão institucional:

- Acompanhar os discentes na execução das atividades normativas e oficializadas pelas instituições a respeito dos estágios, as quais englobam a organização de documentos (como o Termo de Compromisso do Estágio), o cumprimento da carga horária, entre outros (SOARES, 2016; ROCHA, 2018); 
- Coordenar as atividades da universidade com as escolas, espaços de materialização dos estágios, na intenção de desenvolverem e ampliarem boas relações e parcerias (ROCHA, 2018);

- Mediar a relação entre estagiários e professores supervisores da Educação Básica, ou seja, entre os representantes das instituições envolvidas com o desenvolvimento dos estágios, visando o cumprimento de suas atividades e funções (SOARES, 2016; SILVA, 2017);

- Avaliar com as instituições as condições/possibilidades de exequibilidade dos estágios, bem ainda as ações e atividades desenvolvidas com a participação dos sujeitos envolvidos com os estágios supervisionados (ROCHA, 2018).

Em notas conclusivas à discussão sobre o papel formador dos professores orientadores dos estágios supervisionados, inferimos o entendimento de que a orientação nos estágios deve ser concebida, em quaisquer circunstâncias, como orientação formativa, ou seja, como práxis educativa. Para nós, esse entendimento ajuda a pensarmos os processos de formação inicial docente organicamente articulados, sem o dualismo que separa a teoria da prática.

Sabemos, com base em nossas experiências profissionais e no que destacam as teses analisadas, que não é fácil, dadas as inúmeras barreiras que encontramos nas instituições para o desenvolvimento dos estágios: número de alunos para cada professor orientador; ausência de condições que viabilizem o acompanhamento dos estagiários nas escolas pelos professores orientadores; sobrecarga de atividades e funções pelos professores orientadores na universidade; sobrecarga de atividades e funções em sala de aula e nas escolas pelos supervisores dos estágios, entre outros. Contudo, não podemos nos subtrair dessa tarefa como professores formadores de professores.

\section{Considerações finais}

No decurso deste texto, nos esforçamos para apresentar uma leitura teórica e analítica, a partir de um levantamento documental com produções doutorais, sobre os professores orientadores dos estágios supervisionados dos cursos de licenciatura do Brasil. Como eixos principais da análise, destacamos "quem são os professores orientadores dos estágios supervisionados dos cursos de licenciatura do Brasil” e qual "o papel formador desenvolvem nos estágios". A partir dessas referências discutidas no texto, concluímos que a orientação nos estágios supervisionados é um componente essencial nos cursos de licenciatura, haja vista 
que, ao assumir um papel multifacetado, associado às dimensões pedagógicas, curriculares e institucionais nas instituições de ensino (de Educação Superior e de Educação Básica), é determinante na formação inicial docente.

As produções doutorais analisadas apontam que o trabalho de orientação nos estágios vai muito além de orientar e/ou conduzir os discentes em formação nos espaços escolares. Não se resume aos aspectos burocráticos e meramente institucionais. Os professores orientadores, por meio da orientação, exercem o papel de estimuladores da reflexividade e da criticidade acerca da realidade escolar com os estagiários e demais sujeitos envolvidos nos estágios; de geradores de situações que coloquem em xeque os desafios existentes no cotidiano das escolas e da sala de aula, entre outros. Nesse sentido, são elementos importantes na construção do currículo praticado nos cursos de licenciatura do Brasil.

Tendo em vista esses argumentos, defendemos como conclusão deste estudo, que a orientação nos estágios deve ser concebida como orientação formativa, isto é, como práxis educativa. A orientação nos estágios supervisionados contribui para que os professores, os processos de formação inicial e a universidade se associem com o contexto para o qual vislumbram formar docentes: a Educação Básica. De certa forma, é por meio da mediação do trabalho de orientação nos estágios supervisionados que os discentes constroem conhecimentos de natureza diversa a respeito da profissão que exercerão. Assim, a orientação nos estágios supervisionados nas licenciaturas do Brasil é articuladora e produtora da práxis educativa.

Assim, não esqueçamos de que a orientação nos estágios supervisionados só se desenvolve como orientação formativa caso existam condições de efetuá-la, seja a nível institucional e curricular (condições de acompanhamento dos discentes e diálogo com as escolas em que se desenvolvem os estágios, organização do estágio incluindo a pesquisa como mecanismo metodológico das ações, entre outros), seja a nível pedagógico (formação pedagógica e profissional para os professores orientadores sobre a orientação nos estágios, entre outros). Não havendo tais condições para a orientação dos estágios se perspectivar como orientação formativa, reproduziremos, como feito em muitos contextos na história da formação inicial docente no País, discursos esvaziados de sentidos e de significados aos processos formativos de professores, pobres na abstração da realidade e distantes do que ocorre, em verdade, nas instituições escolares e na sala de aula.

Vale, ao final, a importância de se refletir sobre a grande quantidade de teses, dissertações e artigos que discutem o estágio pela perspectiva do estudante de licenciatura, sejam seus aprendizados e/ou angústias. Não obstante, o papel do professor orientador, como 
formador dos licenciandos, não pode ser deixado como está, como se fosse algo pronto e acabado ou, pior, como se já adquirisse todos os saberes necessários a essa importante missão a partir do momento em que se torna orientador. Dessa forma, esperamos que essa pesquisa tenha cumprido seu papel ao trazer destaque para aqueles que têm o desafio de formar futuros professores por meio da atividade de orientação de estágio.

\section{REFERÊNCIAS}

ANDRÉ, Marli. Mestrado Profissional e Mestrado Acadêmico: aproximações e diferenças. Rev. Diálogo Educ., Curitiba, v. 17, n. 53, p. 823-841, 2017.

BRASIL, Lei n. 11.788, de 25 de setembro de 2008. Disponível em: http://www.planalto.gov.br/ccivil_03/_Ato2007-2010/2008/Lei/L11788.htm. Acesso em: 28 mar. 2020.

CARVALHO, Marília Pinto de. Trabalho Docente e Relações de Gênero - algumas indagações. Revista Brasileira de Educação, Rio de Janeiro, n. 2, p. 77 - 84, 1996.

CUNHA, Amélia T. B. da. Sobre a Carreira Docente, a Feminização do Magistério e a Docência Masculina na Construção do Gênero e da Sexualidade Infantil. In: Reunião regional da Anped sul, 9, 2012, Caxias do Sul/RS, Anais... Caxias do Sul: Universidade de Caxias do Sul, 2012.

DANIEL, Luana Amoroso. O professor regente, o professor orientador e os estágios supervisionados na formação inicial de futuros professores de letras. Dissertação (Mestrado em Educação) - Programa de Pós-Graduação em Educação, Universidade Metodista de Piracicaba, Piracicaba, 2009.

GATTI, Bernadete Angelina; BARRETTO, Elba Siqueira de Sá. Professores do Brasil: impasses e desafios. Brasília - DF: Editora da UNESCO, 2009.

GATTI, Bernadete Angelina; et al. Professores do Brasil: novos cenários de formação. Brasília: UNESCO, 2019.

LIMA, Maria Socorro. Estágio e aprendizagem da profissão docente. Brasília: Liber Livro, 2012.

LOURO, Guacyra Lopes. Gênero e Magistério: identidade, história e representação. In: CATANI, Bárbara Denice et al. (org.). Docência, Memória e Gênero: estudos sobre formação. São Paulo: Escrituras Editora, 1997, p. 73 - 83.

LÜDKE, Menga; SCOTT, David. O Lugar do Estágio na Formação de Professores em duas perspectivas: Brasil e Inglaterra. Educação \& Sociedade, Campinas, v. 39, no. 142, p.109$125,2018$. 
MACHADO, Ana Maria Netto. A relação entre autoria e a orientação no processo de elaboração de teses e dissertações. In: MACHADO, Ana Maria Netto; BIANCHETTI, Lucídio (org.). A Bússola do Escrever: desafios na orientação e no processo de escrever teses e dissertações. 3. Ed. São Paulo: Cortez, 2012, p. 45-66.

MARAFELLI, Cecilia Maria; RODRIGUES, Priscila Andrade Magalhães; BRANDÃO, Zaia. A formação de profissional dos professores: um velho problema sob outro ângulo. Cadernos de Pesquisa, São Paulo, v. 47 n. 165 p. 982-997, 2017.

MEDEIROS, Lilian de. Estado da arte das teses e dissertações sobre as licenciaturas: as tendências dos estudos de estágio supervisionados. Dissertação (Mestrado em educação) Pontifícia Universidade Católica do Paraná. Curitiba, 2014.

MONTEIRO, Ana Maria. A prática de ensino e a produção de saberes na escola. In: CANDAU, Vera Maria. Didática, currículo e saberes escolares. Rio de Janeiro: DP\&A, 2002. p. 130- 147.

MONTEIRO, Luana; FORTUNATO, Ivan. A relação entre saberes docentes e a formação continuada: teses e dissertações 2012-2017. Revista Ibero-Americana de Estudos em Educação, Araraquara, v. 14, n. 4, p. 2260-2274, 2019.

NÓVOA, António. Firmar a posição como professor, afirmar a profissão docente. Cadernos de Pesquisa, São Paulo, v. 47, n. 166, p. 1106-1133, 2017.

PIMENTA, Selma Garrido; LIMA, Maria Socorro Lucena. Estágio e docência. 8. ed. São Paulo: Cortez, 2017.

SARTI, Flávia Medeiros. O triângulo da formação docente: seus jogadores e configurações. Educação e Pesquisa, São Paulo, v. 38, n. 2, p. 323-338, 2012.

SCHEIBE, Leda. A formação pedagógica do professor licenciado - contexto histórico. Perspectiva, Florianópolis, v. 1, n. 1, p. 31-45, 1983.

ZEICHNER, Ken. Repensando as conexões entre a formação na universidade e as experiências de campo na formação de professores em faculdades e universidades. Educação, Santa Maria, v. 35, n. 3, p. 479-504, 2010.

\section{Teses inventariadas}

PEREIRA, Sybelle Regina Carvalho. Aprendizagem Docente do Professor Orientador no Estágio Curricular Supervisionado em Cursos de Licenciatura. Tese (Doutorado em Educação) - Universidade Federal de Santa Maria. Santa Maria, 2017.

ROCHA, Luzianny Borges. Os Saberes Docentes do Orientador de Estágio Curricular do Curso de Licenciatura em Geografia. Tese (Doutorado em Educação) - Universidade Federal do Ceará. Fortaleza, 2018.

SILVA, Kátia Silene da. Professoras Orientadoras de Estágio Supervisionado em Curso de Pedagogia: desenvolvimento profissional docente e sentidos atribuídos à função de 
orientação. Tese (Doutorado em Educação) - Universidade Metodista de Piracicaba. Piracicaba, 2017.

SOARES, Maria do Socorro. Estágio Curricular Supervisionado no Curso de Pedagogia da UFPI: tessituras da relação teoria e prática na formação de professores. Tese (Doutorado em Educação) - Universidade Federal do Rio de Janeiro. Rio de Janeiro, 2016.

STAHL, Luana Rosalie. Pedagogia Específica de Orientação de Estágio: uma investigação narrativa. Tese (Doutorado em Educação) - Universidade Federal de Santa Maria. Santa Maria, 2017.

ZIMMER, Iara. Estágio curricular supervisionado na licenciatura em Matemática: um componente curricular em discussão. Tese (Doutorado em Educação) - Pontifícia Universidade Católica de São Paulo. São Paulo, 2018.

\section{SOBRE OS AUTORES:}

\section{Emerson Augusto de Medeiros}

Doutor em Educação pela Universidade Estadual do Ceará (UECE). Professor Adjunto do Departamento de Ciências Humanas da Universidade Federal Rural do Semi-Árido (DCH/UFERSA), Brasil. É membro dos Grupos de Pesquisa "Educação, Memórias, (Auto) Biografia e Inclusão" da Universidade do Estado do Rio Grande do Norte (GEPEMABI/UERN), "Educação, Discursos e Sociedade" (GEPEDS/UFERSA) e "Laboratório de práticas, estudos e pesquisas em formação de professores - Universidade e Escolas de Educação Básica (Laconex@o/UFPB)”. E-mail: emerson.medeiros@ufersa.edu.br (iD https://orcid.org/0000-0003-3988-3915

\section{Ivan Fortunato}

Doutor em Desenvolvimento Humano e Tecnologias e Doutor em Geografia, ambos pela Universidade Estadual Paulista Júlio de Mesquita Filho, Rio Claro. Professor em regime de dedicação exclusiva do Instituto Federal de Educação, Ciência e Tecnologia de São Paulo (IFSP), campus Itapetininga. Professor permanente do Programa de Pós-Graduação em Educação da UFSCar, campus Sorocaba. E-mail: ivanfrt@yahoo.com.br.

(iD https://orcid.org/0000-0002-1870-7528.

\section{Osmar Hélio Alves Araújo}

Doutor em Educação pela Universidade Federal da Paraíba (UFPB). Professor Adjunto do Departamento de Educação da Universidade Federal da Paraíba (UFPB), Brasil. É Líder do Grupo de Pesquisa "Laboratório de práticas, estudos e pesquisas em formação de professores - Universidade e Escolas de Educação Básica (Laconex@o/UFPB)”. E-mail: osmarhelio@hotmail.com

iD https://orcid.org/0000-0003-3396-8205 